\title{
Vitamin K-biofortification of eggs: effect on egg quality and hen performance parameters
}

\section{Abstract}

Vitamin K has important physiological functions which relate to blood coagulation (its classical role), bone health, inhibition of arterial calcification, as well as anti-inflammatory effects. National nutrition survey data have shown that over half of all adults in Ireland and the UK have low vitamin $\mathrm{K}_{1}$ intakes $(£ 1 \mu \mathrm{g} / \mathrm{kg}$ body weight $/ \mathrm{d})$. Vitamin $\mathrm{K}$ biofortification of food may be an important complementary food-based approach for improving vitamin $\mathrm{K}$ intakes. Our study aimed to explore the feasibility of producing vitamin K-biofortified eggs via increasing the vitamin $\mathrm{K}_{3}$ content of the hen diet, and to examine any effects on hen performance and egg/ eggshell quality parameters. A 12-week hen feeding trial was conducted in the Agri-Food and Biosciences Institute, Belfast, UK. Hyline chickens $(n=128)$ were randomized into 4 treatment $(T)$ groups $(n=32$ hens/group) and fed diets containing 3 (T1-industry standard), 12.9 (T2), 23.7 (T3) and 45.7 (T4) $\mathrm{mg}$ vitamin $\mathrm{K}_{3} / \mathrm{kg}$ of feed. Hens were provided feed ad libitum and feed intake was recorded weekly. Eggs were collected daily and weighed. While egg quality and vitamin $\mathrm{K}$ content was assessed at week $0,4,6,8$ and 12, the trial endpoint (week 12) data was prioritized for the current analysis. Total vitamin $\mathrm{K}$ content (i.e., vitamin $\mathrm{K}_{1}$ plus menaquinone (MK)-4 and MK-7) of composite samples ( $\mathrm{n}=12$ eggs/treatment), measured using a novel, sensitive liquid chromatography-mass spectrometry method at Teagasc, increased from $22.4 \mu \mathrm{g} / 100 \mathrm{~g}$ (whole egg) in T1 (control and commercial level of vitamin $\mathrm{K}_{3}$ ) to $57.8 \mu \mathrm{g} / 100 \mathrm{~g}$ in $\mathrm{T} 4$. MK-4 was the most abundant form of vitamin $\mathrm{K}$ found in the eggs. Eggshell weight and eggshell thickness in T2 and T3 (but not T4) were significantly higher than in T1 (by $20-28 \%, P<0.05$ ). Likewise, based on colourimetric assessment, yellowness (parameter $b^{*}$ ) of the egg yolk in all three biofortified groups was significantly higher compared to T1 (by $27-45 \%, P<0.05$ ). Haugh unit of the eggs and hen performance parameters, such as feed intake, feed conversion ratio and egg production, were unaffected by vitamin K-biofortification. In conclusion, increasing the level of addition of vitamin $\mathrm{K}_{3}$ to hen feed significantly increased the total vitamin $\mathrm{K}$ content of eggs, and without any evidence of negative effects on egg quality or hen performance. Consumption of an average sized $(60 \mathrm{~g})$ vitamin K-biofortified egg could contribute an additional $35 \mu \mathrm{g}$ total vitamin $\mathrm{K}$. The effects on eggshell parameters could be of importance in terms of revenue loss due to breakages.

\section{Conflict of Interest}

There is no conflict of interest 